\title{
WITNESSING CPR OF A FELLOW PATIENT IN HOSPITAL: A QUALITATIVE STUDY EXPLORING PATIENTS" EXPERIENCES
}

Martina Fiori ${ }^{1}$, Clara Cutello ${ }^{2}$, Ruth Endacott ${ }^{1}$, Maureen Coombs ${ }^{1}$, Jos M. Latour ${ }^{1}$

${ }^{1}$ School of Nursing and Midwifery, University of Plymouth (UK), ${ }^{2}$ School of Psychology, University of Plymouth (UK)

\section{BACKGROUND AND AIM}

Witnessing CPR in or out hospital is a stressful experience for bystanders. Substantial improvements have been made in supporting family presence during hospital CPR. However, the perspectives of fellow patients on witnessed CPR in hospital are still relatively unknown.

The aim of this study is to explore the lived-experience of hospital patients who witness CPR on another patient.

\section{METHODS}

We designed an exploratory qualitative study with a phenomenological approach. We conducted individual face-to-face interviews with $\mathrm{N}=17$ hospital patients who witnessed CPR on another patient in the same multi-bed room, within one week after CPR. Interviews were audio-recorded, transcribed and managed into NVivo 12 and subject to descriptive phenomenological analysis.

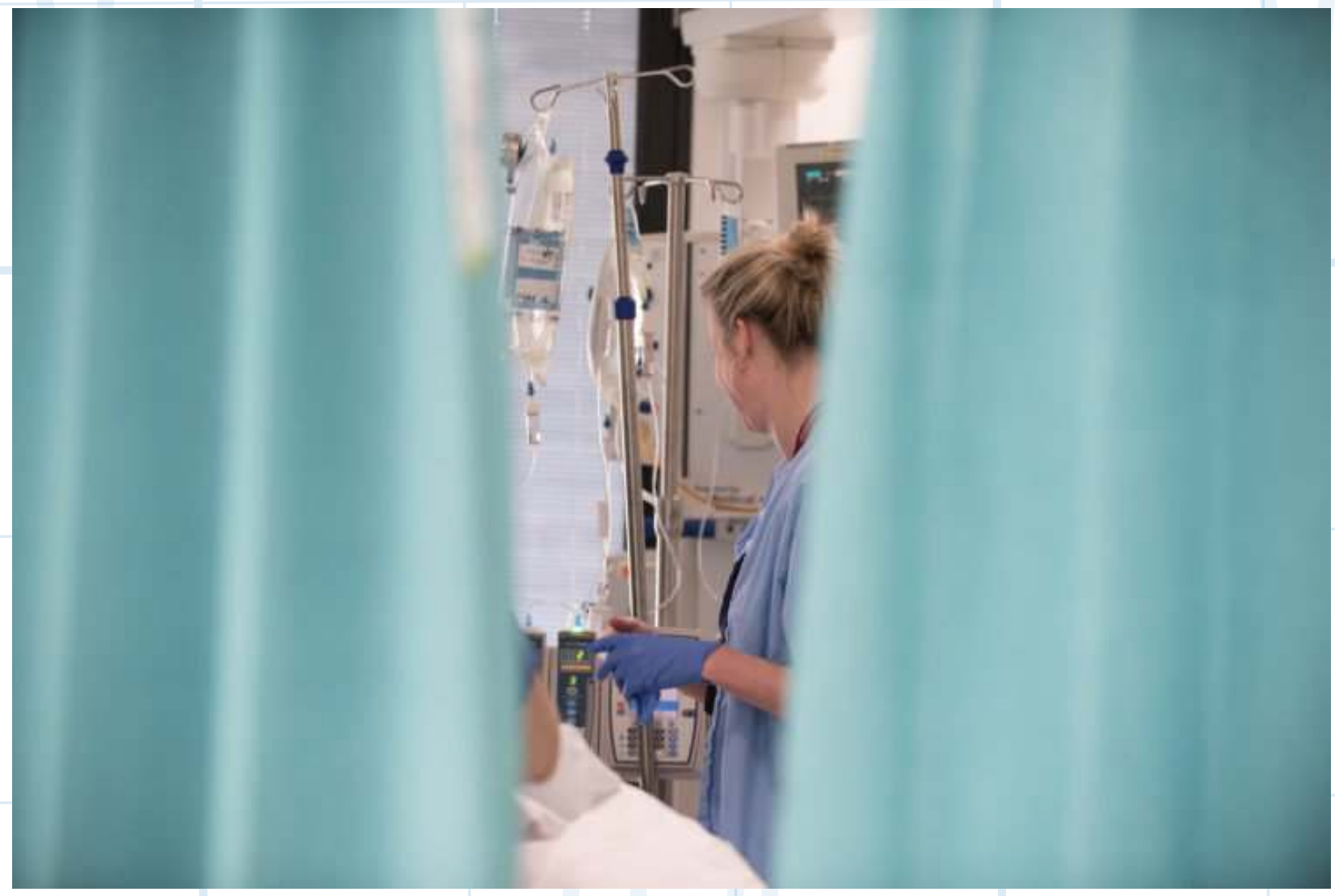

Freepik Company ${ }^{\circledR}$

\section{CONCLUSIONS}

This study provides new insight on the experience of patients who witness CPR in hospital. Witnessing CPR in hospital can be traumatic for patients. Healthcare professionals should acknowledge the presence of patients witnessing CPR and enhance the practice of patient debriefing after CPR to help them feel considered, reassured and supported.

\section{FINDINGS}

Four themes were developed from the analysis of the interviews, providing a rich understanding of patients' witnessing experience.

- Patients are aware of the reality of hospital and accept that cardiac arrests and CPR are an element of their hospital experience.

- Witnessing CPR of a fellow patient is a negative experience, having an emotional impact on patients, who react with different coping strategies.

- Patients do not feel protected by bed-curtains but feel stuck and exposed to the noise of CPR. In turn, they feel safe when observing staff's prompt response to the emergency.

- Patients need to receive information and reassurance from healthcare professionals after witnessing CPR on another patient to feel supported.
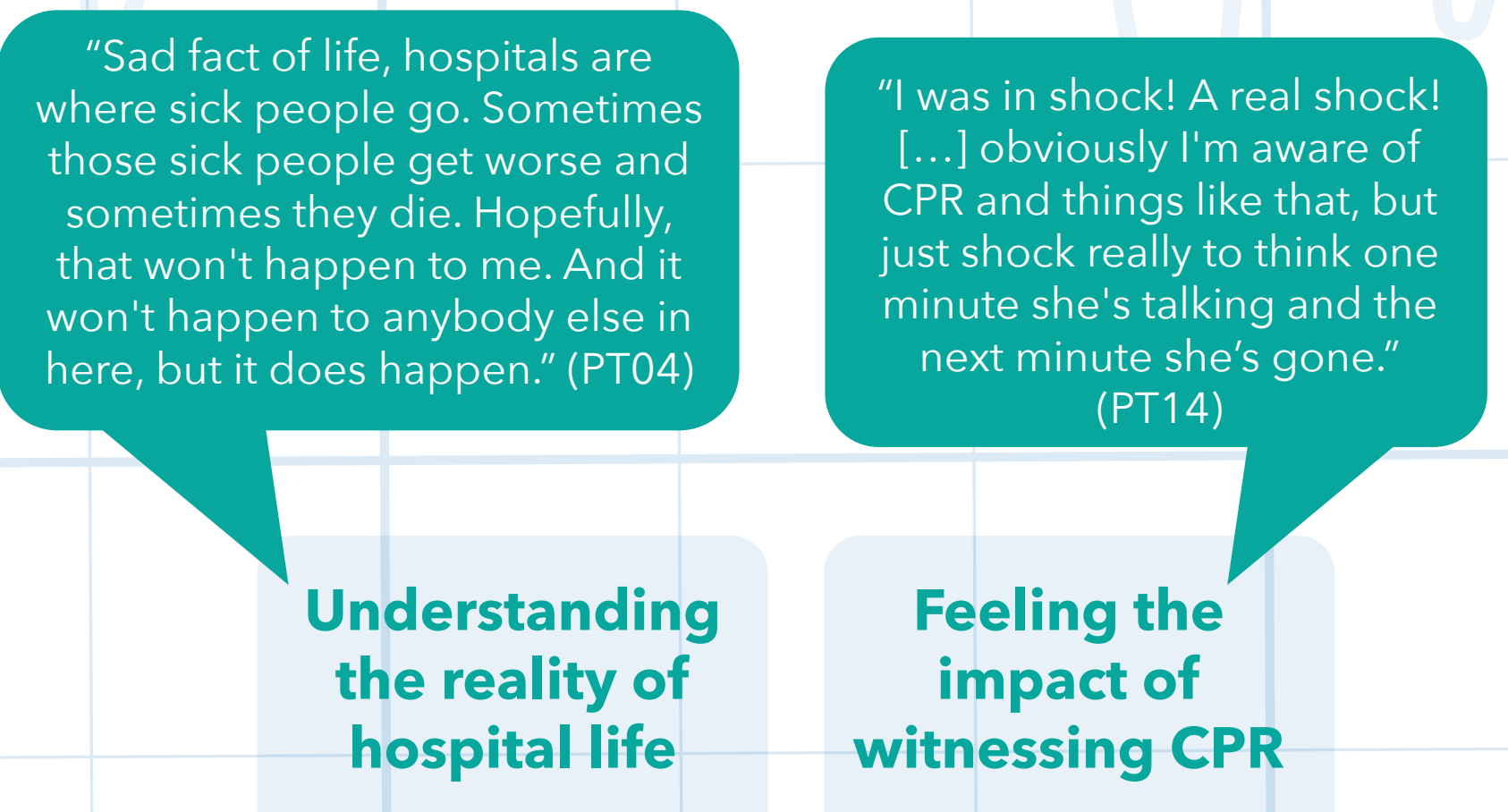

Feeling stuck and feeling safe: an unintended effect

\section{Receiving support from the staff}
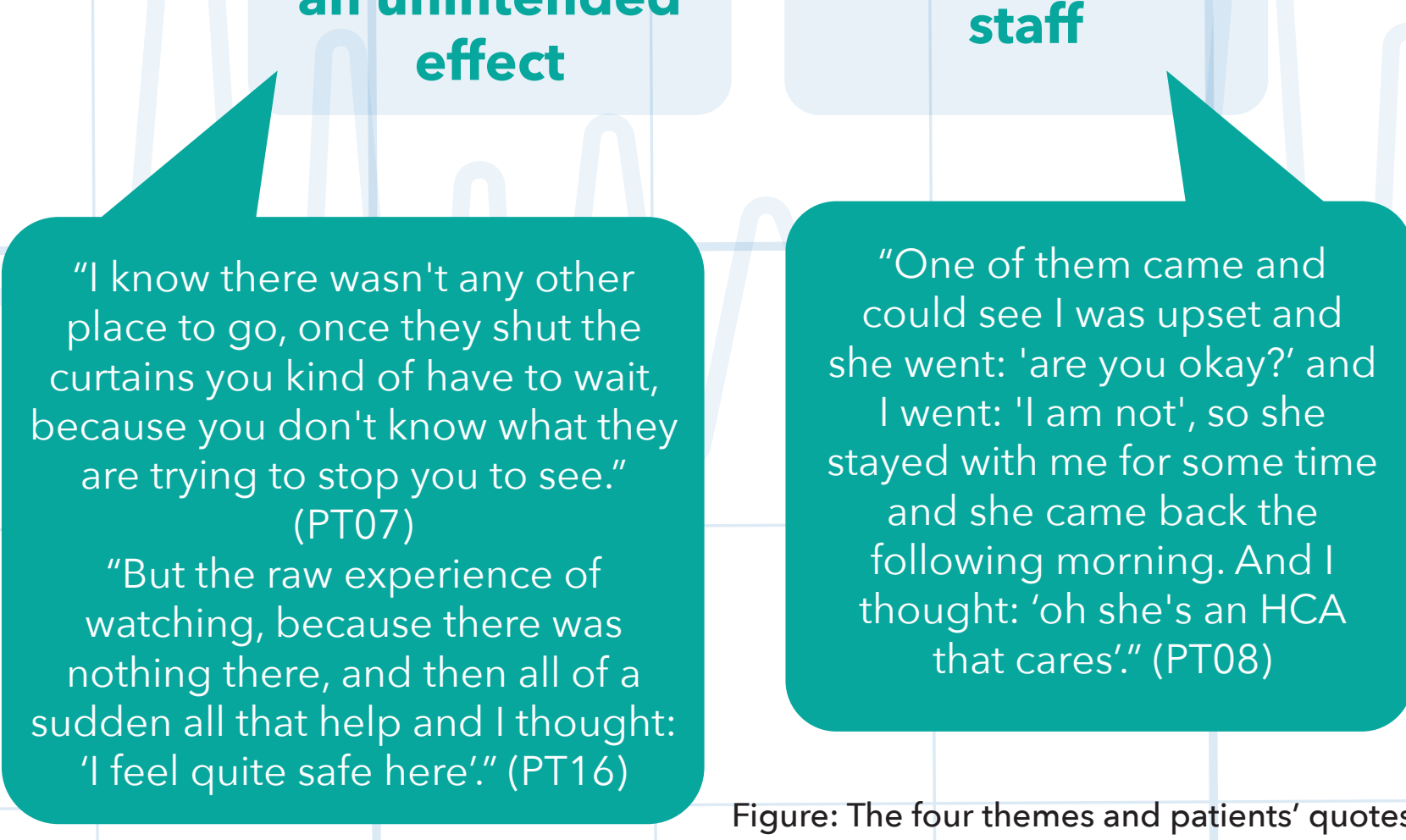

Figure: The four themes and patients' quotes

CONTACTS: martina.fiori@plymouth.ac.uk

ORCID iD: https://orcid.org/0000-0001-7862-0267 